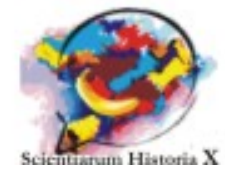

\title{
Os prontuários e leis psiquiátricas como fonte historiográfica e etnográfica da reforma psiquiátrica brasileira: Novos modos de governamentalidade?
}

\section{Psychiatricrecordsandlaws as a \\ historiographicalandethnographicsourceofBrazilianpsychi \\ atricreform: New modesofgovernmentality?}

\section{Adriana Beatriz Molas Quintana}

Programa de Pós-Graduação em História das Ciências e das Técnicas e Epistemologia (HCTE), Universidade Federal do Rio de Janeiro (UFRJ).

adrimolas@gmail.com

orcid.org/0000-0002-6743-5071

\section{Arthur Arruda Leal Ferreira}

Professor Titular do Instituto de Psicologia (IP), Universidade Federal do Rio de Janeiro (UFRJ).

arleal1984@gmail.com.br

orcid.org/0000-0002-2059-8877

\section{Rafael de Souza Lima}

Doutorando no Instituto de Psicologia Psicologia, Universidade Federal do Rio de Janeiro (UFRJ).

rdsl.1989@gmail.com

orcid.org/0000-0002-1351-4970

\section{Letícia Gomes Canuto}

Mestre em História das Ciências e das Técnicas e Epistemologia

Graduanda no Instituto de Psicologia (IP), Universidade Federal do Rio de Janeiro

(UFRJ).

lgomescanuto@gmail.com 
orcid.org/0000-0001-8146-5931

\title{
Bárbara Victor Souza
}

Graduanda no Instituto de Psicologia (IP), Universidade Federal do Rio de Janeiro (UFRJ)

souza.barbaravictor@gmail.com

\section{Laiz Rangel Barbosa}

Graduanda no Instituto de Psicologia (IP), Universidade Federal do Rio de Janeiro (UFRJ).

laizrb@gmail.com

orcid.org/0000-0001-5357-900X

\section{Nicole Marques Simões da Silva}

Graduanda no Instituto de Psicologia (IP), Universidade Federal do Rio de Janeiro

(UFRJ).

\author{
nicole.marcques@hotmail.com \\ orcid.org/0000-0003-0729-1800
}

Resumo. A partir do trabalho genealógico de Foucault sobre as práticas de governo, abre-se um campo possível para o estudo das práticas e nos saberes psicológicos e psiquiátricos. Aqui teríamos dois marcos: 1) no século XVI, surgem técnicas de governo baseadas no disciplinamento, o "Estado de polícia"; e 2) no século XVIII novas tecnologias de governo em referências liberais. Nosso objetivo é avaliar as práticas e conceitos de cidadania e liberdade no contexto de alguns processos de Reforma Psiquiátrica Brasileira. Para tal, sustentamos que coexistem neste campo não apenas os antigos dispositivos disciplinares e a resistência a estes, mas modos liberais de gestão. Estes serão analisados nas práticas cotidianas de gestão dos usuários em saúde mental, presentes em textos, leis e prontuários.

Palavras-chave: Reforma psiquiátrica. Governamentalidade. Práticas de liberdade. 


\begin{abstract}
FromFoucault'sgenealogicalworkongovernmentpractices, possiblefieldisopened thestudyofpsychologicalandpsychiatricpracticesandknowledge.

Herewewouldhavetwomilestones: 1) in the 16th century, governmenttechniquesbasedondisciplining, the "policestate"; and 2) in the 18th century, new governmenttechnologies in liberal references. Ourobjectiveistoevaluatethepracticesandconceptsofcitizenshipandfreedom in thecontextof some processes ofBrazilianPsychiatric Reform. Tothisend, wemaintainthatnotonlytheolddisciplinary devices andtheresistancetothese, but liberal modesof management coexist in thisfield. Thesewillbeanalyzed in thedaily management practicesofusers in mental health, present in texts, lawsand medical records.
\end{abstract}

Keywords:Psychiatric reform. Governmentality. Freedompractices.

Recebido: 01/10/2017 Aceito: 27/10/2017 Publicado: 05/11/2017

\title{
1. Introdução: Abrindo cenários
}

Em meados do século XX despontaram em diversos países europeus e americanos uma série de movimentos que apresentaram alternativas aos modos de abordagem da psiquiatria tradicional, centrada então na figura do asilo manicomial. Muitos destes movimentos (como a Antipsiquiatria Britânica e a Psiquiatria Democrática Italiana) produziram inclusive abordagens mais radicais, que questionaram não apenas o asilo como pedra fundamental do tratamento, mas também o estatuto da própria psiquiatria como saber e prática. Especialmente estes últimos movimentos têm proposto palavras-de-ordem e termos-chave que até então eram incompatíveis com as práticas psiquiátricas: liberdade, cidadania e direitos humanos. Igualmente, têm aberto territórios até então impossíveis para os pacientes: ruas, assembleias, trabalho livre, consumo, responsabilidade e autogestão.

Também têm permitido a entrada em jogo de outros profissionais nos serviços de atenção aos usuários: psicólogos, sociólogos, terapeutas ocupacionais e servidores sociais. Estas novidades se materializam em instituições de portas abertas, leis, políticas governamentais e principalmente em práticas cotidianas de cuidado e gestão dos usuários. Em poucas décadas, os serviços de atenção aos ditos doentes mentais se transformou de forma substancial: o asilo praticamente desapareceu como dispositivo central e a psiquiatria perdeu seu protagonismo diante do ativismo dos demais profissionais e dos pacientes. Estes processos geralmente são celebrados como verdadeiras "revoluções" que libertaram a "loucura" das correntes da velha psiquiatria (ver por exemplo AMARANTE, 1998). 
O que propomos, de modo diferente, é abordar os processos de reforma psiquiátrica a partir de uma descrição dos dispositivos de gestão cotidiana através do conceito-operador de govenamentalidade, proposto por Foucault (2006 e 2007). Não é nosso objetivo criticar o processo de reforma da instituição psiquiátrica, nem defender supostas propostas conservadoras que a criticam: estas, quando ocorrem, propõe geralmente um controle mais estrito dos usuários. Nosso objetivo não é pôr em questão as diretrizes gerais dos movimentos reformistas, e sim analisar seus dispositivos específicos em relação aos modos de governo aí presentes. Estudaremos primeiro o conceito de governamentalidade, introduzido por Foucault no fim dos anos 70. Este conceito pode ajudar na descrição de alguns dispositivos cotidianos presentes nos processos de reforma psiquiátrica brasileiros. $\mathrm{Na}$ conclusão, discutiremos o sentido das práticas de liberdade presente nestas práticas, abrindo um espaço de debate para novas formulações destes modos de gestão.

\section{Governamentalidade e estratégias "psi"}

Em dois cursos oferecidos no fim dos anos 1970 no Collège de France, Segurança, Território e População (2006) e o Nascimento da Biopolítica (2007), Foucault introduz o conceito de governamentalidade, entendido como o exercício estratégico de controle da conduta alheia. De forma mais específica este seria "o conjunto constituído pelas instituições, os procedimentos, análises e reflexões, os cálculos e as tácticas que permitem exercer esta forma específica, mesmo que muito complexa de poder, que têm por objetivo a população" (FOUCAULT, 2006, p. 136). Conforme Foucault (2006), um momento decisivo na história das artes de governo se situa no século XVI, quando surgem os chamados "Manuais de Governo". Os autores desses manuais (por exemplo, La Perriére na França, Mayenne na Holanda, Huhental na Alemanha) são em geral completamente desconhecidos para nossa reflexão política atual. Esses manuais possuíam uma série de dispositivos pelos quais o Estado deveria administrar não somente o fluxo de mercadorias, mas também os populacionais, que assim se torna um assunto de governo.

Preocupações deste tipo aumentavam conforme se evidenciava uma urbanização acelerada produzida pela migração rural e o descenso da taxa de mortalidade. Gradualmente a noção de população vai definindo seus contornos, passando a ser vista como uma entidade capaz de gerar riqueza e poderio econômico. Estes manuais surgiram ao mesmo tempo em que apareceram novas doutrinas e dispositivos relativos aos Estados, que se agrupam no Estado de Polícia, que inclui recursos para registrar e corrigir as ações dos indivíduos. Os métodos disciplinares haviam sido uma marca presente nos séculos XVI e XVII, atuando na vigilância contínua e no controle dos corpos e atos em instituições como escolas e casernas. Em meados do século XVIII o movimento fisiocrata postula a necessidade de estabelecer limites quanto à atuação deste Estado de Polícia sobre os mercados. Isto devido à suposição 
de que os fenômenos do mercado obedeceriam a uma ordem natural e a leis inerentes a ela. Este é o deslocamento básico com que os governos liberais operam em relação aos dispositivos disciplinares do Estado de Polícia. No entanto, a esta transformação, se segue outra mais fundamental no interior das próprias estratégias liberais a partir dos séculos XIX e XX: se no século XVIII o liberalismo se afirmava como uma crítica do Estado, a partir do século XIX e especialmente do XX, ele passa a oferecer técnicas positivas de governo, como o ordoliberalismo alemão e neo-liberalismo norte-americano. Foucault $(2006 ; 2007)$ e Rose (1998) sugerem que o surgimento do liberalismo coloca o domínio da população como nova preocupação do governo, que necessitaria descobrir meios para dirigi-la, respeitando seus códigos naturais de funcionamento. Por tanto, se tornaria absolutamente necessário o conhecimento de seus padrões de ação, de suas regularidades, a fim de conduzir os indivíduos como sujeitos responsáveis. É este contexto onde a psicologia encontra as condições de seu desenvolvimento: como saber legitimado sob a promessa de cientificidade e livre condução da conduta alheia.

Para Rose (1998), a história dos saberes psi está ligada a história do governo de uma dupla forma: 1) mediante as técnicas de inscrição que permitem que as subjetividades se tornem permeáveis às técnicas de governo; e 2) mediante a constituição de políticas múltiplas que pretendem conduzir a conduta dos indivíduos, ainda que não somente através da disciplina, mas principalmente através da liberdade e da atividade destes. Nos trabalhos de Rose e Foucault, o liberalismo se configura como uma técnica positiva de gestão que se origina no domínio econômico, mas que se desloca pouco a pouco em direção à questão da população em geral. A psicologia possuiria especial importância nestas novas técnicas governamentais liberais, operando especialmente na construção das formas democráticas de associação, buscando estimular modos mais livres e ativos de conduta por parte dos cidadãos. No entanto, tomado numa perspectiva panorâmica a história das práticas relacionadas com o campo da saúde mental apresentaria um caminho singular: estas técnicas governamentais revelam uma passagem de dispositivos exclusivamente disciplinares (como os asilos) para os modos de governo embasados na soberania e, principalmente, nas formas liberais (gestão em espaços livres). Nosso objetivo será avaliar especificamente as práticas governamentais presentes nos discursos e práticas reformistas. A análise das técnicas governamentais presentes nestes processos de reforma será levada a cabo através do estudo de (a) documentos oficiais (lei, normativas e resoluções) e (b) da descrição das práticas cotidianas presentes nos processos reformistas, especialmente as presentes nos prontuários.

\section{Um novo modo de governar por meio da liberdade e da autonomia}


É possível dizer que o esforço central dos processos de reforma psiquiátrica no Brasil é excluir as antigas formas de governo dos ditos doentes mentais presentes nas instituições asilares. Isto abre espaço a formas de gestão calcadas na soberania, como a participação de entidades públicas na decisão das internações: o Ministério Público (BRASIL, 2002), ou ainda a lei antimanicomial brasileira decretada em 2001 (BRASIL, 2002). Porém, nossa hipótese é que junto a estas novas práticas legais surgem formas cotidianas de gestão liberal. Isto poderia ser visto de alguma forma como uma contradição, especialmente considerando a forte tendência esquerdista e contestatória presentes nos movimentos reformistas. Mas como Foucault (2006) destaca, tal contradição se resolve levando-se em conta que as práticas políticas de esquerda não têm produzido nenhuma forma nova de governamentalidade, apesar da inovação de suas teorias políticas.

Os CAPS (Centro de Atenção Psicossocial) no Brasil são dispositivos-chave para as novas práticas no tratamento das ditas doenças mentais e seus modos de funcionamento se baseiam em uma rede que conecta diversos serviços com familiares e a comunidade de entorno. O sujeito de intervenção nestes novos dispositivos deve deslocar-se livremente por esta rede, o que implicaria na obtenção de certas habilidades necessárias de autorresponsabilidade ou o autogoverno. Os pacientes seriam assim estimulados a obter um papel ativo em seu próprio tratamento e na construção de relações sociais. Estas atividades têm por objetivo desenvolver no paciente "uma forte integração social e familiar, a expressão de sentimentos e problemas, o treinamento de habilidades corporais, o trabalho em atividades produtivas, e o exercício coletivo da cidadania" (BRASIL, 2004, p. 20). Um exemplo bom e prático do reforço da atividade nos pacientes é o estímulo a participar nas assembleias coletivas. Aqui, o suposto doente mental obteria uma real possibilidade de decidir e determinar os destinos de seu próprio tratamento (BRASIL, p. 17).

Além destas abordagens presentes nos documentos oficiais, é importante considerar narrativas etnográficas (SILVA, 2005) onde se descreve toda a rede cotidiana de práticas de responsabilidade contra a internação e a favor da liberdade dos pacientes. Estas formas de intervenção dão conta de uma rede de múltiplos atores, como profissionais (psiquiatras, psicólogos, trabalhadores sociais, técnicos de referência, etc.), familiares, a comunidade e o próprio paciente, que por meio de promessas, acordos e recompensas vão criando uma série de dispositivos locais articulados em função de um novo imperativo de liberdade. No Brasil, estas complexas negociações envolvem inclusive a criação de um especialista nas equipes multidisciplinares, o dito técnico de referência. Uma fonte muito interessante de análise desta rede cotidiana de práticas de responsabilidade pode ser encontrada nos prontuários dos pacientes. Nestas fontes é possível observar um estilo discursivo bastante distinto entre diversos profissionais (médicos, enfermeiros, psicólogos e assistentes sociais). Mas, apesar das diferenças estilísticas (as preocupações farmacológicas dos médicos ou as descrições do entorno comunitário dos assistentes sociais) há uma narrativa comum de 


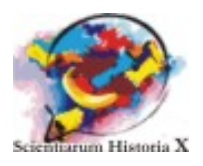

esforços que tangem a mudança nas relações familiares, a busca de um aprendizado profissional, a realização de cursos ou oficinas. Um caso nos chamou muito a atenção no funcionamento de um CAPS que servia a uma área próxima a de um antigo asilo psiquiátrico ${ }^{1}$. No prontuário de uma paciente específica ${ }^{2}$, é possível encontrar a narrativa de uma série de tentativas de internação por parte desta, sendo estas tentativas contornadas com a oferta de uma complexa rede de negociações em torno da oferta de cursos, atividades e reencontros familiares, evitando de toda a forma o recurso pleiteado pela usuária.

$\mathrm{Na}$ sequência da pesquisa, vários casos semelhantes foram encontrados em diferentes $\mathrm{CAPS}^{3}$. O que pôde ser encontrado em comum são diferentes estratégias em prol da autonomia dos usuários dos centros, contornando-se ao máximo qualquer possibilidade de internação destes. Se as regras atuais do jogo apontam para a busca de máxima autonomia e mínima possibilidade de internação, as estratégias encontradas no exame com os prontuários apontam para diferentes práticas de governamentalidade. Em alguns casos, como o relatado no parágrafo anterior, claramente há uma negociação direta com o usuário, ampliando suas margens de autonomia, seja na obtenção de emprego ou trabalho, seja no acompanhamento de atividades ou cursos, seja no incremento de seus vínculos com a vida coletiva. No entanto, em uma parte significativa dos casos, esta negociação não é feita com o usuário, seja pela suposta gravidade do caso, seja pela dificuldade do usuário em aderir ao tratamento. Nestas situações, existe uma busca de acordos e negociações com familiares, amigos, conhecidos ou membros da comunidade. Um aspecto interessante revelado pela pesquisa é, então, que uma série de atores não profissionais são constantemente recrutados pelos atuais serviços de saúde mental a zelar pela autonomia dos usuários. Portanto, além de uma série de novos profissionais e de um novo ator, o técnico de referência, as novas políticas de saúde mental recrutam familiares, amigos, conhecidos e membros comunitários para papéis mais ativos em distintos graus, conforme o caso. Deste modo, estes novos personagens não profissionais atuam frequentemente como acompanhantes dos usuários, assim como pontos centrais destas novas formas de gestão pela e para a liberdade.

\section{Conclusão}

${ }^{1}$ No caso, o CAPS Clarice Lispector foi inaugurado em 2005 no Bairro do Encantado no Rio de Janeiro, a poucas quadras do antigo Hospital psiquiátrico Pedro II, atualmente Nise da Silveira. A expectativa é que este CAPS pudesse absorver boa parte da clientela de pacientes cronificados após longas internações no antigo hospital psiquiátrico.

${ }^{2} \mathrm{O}$ nome da paciente em questão é mantido em sigilo (mesmo tratando-se de um prontuário) de acordo com o que indica a resolução $\mathrm{n}^{\circ} 466$, de 12 de dezembro de 2012. A pesquisa que permitiu ocontato com este prontuário em específico está aprovada pelo Comitê de Ética em Pesquisa do CFCH/UFRJ desde 2016.

${ }^{3}$ Além do CAPS Clarice Lispector, esta pesquisa tem analisado casos no CAPS Rubens Correa, o primeiro a ser aberto na cidade do Rio de Janeiro. 


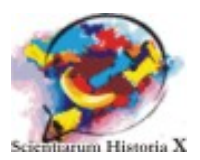

Nosso principal objetivo não é afirmar que os atores da reforma psiquiátrica brasileira têm se limitado a incluir a dita doença mental em uma forma liberal de gestão (ao menos no sentido doutrinário). O que gostaríamos de destacar é a semelhança estratégica destas formas cotidianas de governo da vida dos usuários e profissionais com técnicas como as empreendoristas (Rose, 1998), mesmo quando inseridas em distintas macropolíticas governamentais. Neste sentido, é necessário recordar que as práticas de resistência (como a luta antimanicomial brasileira dos anos 1970) podem se transformar em técnicas positivas de governo, como Foucault (2006) muitas vezes sublinhou em relação a algumas técnicas confessionais. Este caráter mutante e múltiplo das formas de governo é um aspecto ao qual todos os pesquisadores deste campo devem permanecer atentos. À guisa de conclusão, cremos que, no atual conjunto de modos de liberdade e tutela, é crucial repensar a cidadania e a liberdade buscadas pelos dispositivos reformistas em outro sentido: seria necessário perguntar se é possível criar novos modos de cidadania e liberdade fora do horizonte das práticas de autogoverno ou da autonomia negociada. Consideramos que seria interessante tomar a palavra liberdade (tão invocada nos discursos legais e nas práticas reformistas) em modulações distintas das liberais, que a conformam a uma prática governamental de autoempreendimento, autoconstituição e autogestão. Tal como Larrosa (2000) destaca, é necessário "libertar a liberdade" de todas as práticas que fazem desta palavra algo débil. Este exercício é importante para o que Foucault (1995) denomina uma "história crítica do presente", abrindo nossa atualidade para outras possibilidades distintas do que tem sido naturalizado e cristalizado. A liberdade aqui não deve ser entendida como um atributo natural da natureza humana, e sim como um efeito de práticas críticas de resistência e problematização de nossas verdades mais cotidianas. Não seria no caso uma utopia, mas uma heterotopia. A liberdade pode não ser entendida apenas como autogestão. Ela pode implicar "um acontecimento, uma experimentação, uma transgressão, uma ruptura, e uma criação" (Larrosa, 2000, p. 331). Para concluir, gostaríamos de levantar uma posição efetiva para os movimentos reformistas baseada em um uso crítico e heterotópico da palavra liberdade: prestar atenção aos problemas atuais e específicos, e colocar em questão qualquer solução utópica para a loucura, incluindo qualquer solução libertadora.

\section{Financiamento}

O presente trabalho foi realizado com apoio da Fundação de Amparo à Pesquisa do Estado do Rio de Janeiro (FAPERJ), por meio da Bolsa Cientista do Nosso Estado (2015; Número do processo: E-26/203.212/2015). 


\section{Referências}

AMARANTE, P. Loucos pela vida. Rio de Janeiro: Fiocruz, 1998.

BIRMAN, J.A cidadania tresloucada: notas introdutórias sobre a cidadania dos doentes mentais. In: BEZERRA JR., B. e AMARANTE, P. (Eds.). Psiquiatria sem hospício: Contribuições ao estudo da reforma psiquiátrica. Rio de Janeiro: Relume-Dumará, 1992.

BRASIL. Lei ${ }^{\circ}$ 10.216. In: Legislação em Saúde Mental. Brasília: Ministério da Saúde, 2002.

FOUCAULT, M. Seguridad, territorio, población. Buenos Aires: Fondo de Cultura Económica, 2006.

FOUCAULT, M. Nacimiento de la biopolítica. Buenos Aires: Fondo de Cultura Económica, 2007.

LARROSA, J. A libertação da liberdade. In G. C. Branco e V. Portocarrero (eds.), Retratos de Foucault. Rio de Janeiro: Nau, pp. 328-335, 2000.

BRASIL. Saúde mental no SUS: os centros de atenção psicossocial. Brasília: Ministério da Saúde, 2004.

ROSE, N. Inventingourselves. Cambridge: Cambridge University Press, 1998.

SILVA, M. B. Atenção Psicossocial e Gestão de Populações: Sobre os Discursos e as Práticas em Torno da Responsabilidade no Campo da Saúde Mental. Rio de Janeiro: PHYSIS: Rev. Saúde Coletiva, 15(1), p.127-150. 